BULLETIN Bulletin hispanique

HISPANIQUE Université Michel de Montaigne Bordeaux

122-1 $\mid 2020$

Variations donjuanesques

\title{
Teoría(s) de la novela moderna en España. Revisión
} historiográfica

Genueve ediciones, col. Ciencias Sociales y Humanidades, 2019

\section{Geneviève Champeau}

\section{(2) OpenEdition}

\section{Journals}

Edición electrónica

URL: http://journals.openedition.org/bulletinhispanique/11021

DOI: 10.4000/bulletinhispanique.11021

ISSN: 1775-3821

\section{Editor}

Presses universitaires de Bordeaux

\section{Edición impresa}

Fecha de publicación: 18 junio 2020

Paginación: 369-371

ISBN: 979-10-300-0592-9

ISSN: 0007-4640

\section{Referencia electrónica}

Geneviève Champeau, «Teoría(s) de la novela moderna en España. Revisión historiográfica», Bulletin hispanique [En línea], 122-1 | 2020, Publicado el 18 junio 2020, consultado el 19 enero 2021. URL: http://journals.openedition.org/bulletinhispanique/11021 ; DOI: https://doi.org/10.4000/ bulletinhispanique.11021

Este documento fue generado automáticamente el 19 enero 2021

Tous droits réservés 


\title{
Teoría(s) de la novela moderna en España. Revisión historiográfica
}

\author{
Genueve ediciones, col. Ciencias Sociales y Humanidades, 2019
}

Geneviève Champeau

\section{REFERENCIA}

Teoría(s) de la novela moderna en España. Revisión historiográfica. Bénédicte VAUTHIER

(coord. y ed.), Genueve ediciones, col. Ciencias Sociales y Humanidades, 2019, 322 págs.

1 Bénédicte Vauthier reúne doce contribuciones, encabezadas por una extensa introducción de 54 páginas con el propósito de cuestionar las periodizaciones convencionales establecidas por las historias de la literatura a partir de criterios como siglos, generaciones, movimientos, escuelas, que generan una "segmentación historicista" de la historia de la novela. El objetivo del libro es proponer una nueva historiografía literaria fundada en una concepción "hojaldreada" del tiempo, procedente de Koeselleck para quien el tiempo histórico de la Edad Moderna es heterogéneo, compuesto de estratos múltiples vividos simultáneamente (Vauthier, p. 55). Semejante concepción del tiempo invita a superar la mera oposición entre sincronía y diacronía en beneficio de la búsqueda de dis/continuidades, en el marco de una "poética histórica" de la novela que sustituya a los criterios historicistas generadores de discontinuidades una historia de las formas y sus evoluciones asentada en "un diálogo intergeneracional e internacional" (p.16). Hace suya la propuesta de Ricardo Gullón (Prólogo a La novela lírica, 1984) para quien "aproximarse a la novela según sus formas y no según épocas o 'generaciones' permite establecer entre las obras asociaciones iluminadoras" (p. 13).

2 Se da al término 'forma' una acepción amplia que abarca, más allá de estructuras, enunciaciones y otras categorías que distinguen la narratología y la estilística, distintas concepciones de la novela y de la literatura, corrientes de fondo que emergen y se vuelven hegemónicas, pasan a un segundo plano antes de reaparecer, remozadas, en 
nuevas circunstancias. Se supone que, estrictamente hablando, una historia de las formas -a la que aspiraba Gérard Genette- debería asentarse en análisis textuales mientras que este libro se dedica a las teorías de la novela, formuladas en ensayos o presentes en la dimensión metaliteraria de las obras. De hecho, el volumen se organiza alrededor de un eje vertebrador, el tira y afloja entre dos estéticas, realismo y antirrealismo, novela mimética y antimimética, de 1868 (publicación de la primera novela de Galdós, La Fontana de Oro) a 1966 (giro hacia el experimentalismo).

3 Aunque la reflexión sobre teoría de la novela en el siglo XX ha tenido escaso reconocimiento fuera de España, este conjunto de contribuciones rebate la idea de su inexistencia. Si bien se apoyan los diferentes capítulos en obras teóricas como Ideas sobre la novela y La deshumanización del arte de Ortega y Gasset (1925), El nuevo romanticismo de José Díaz Fernández (1930), La hora del lector de José María Castellet (1957), Problemas de la novela de Juan Goytisolo (1959), La inspiración y el estilo de Juan Benet (1966), subrayan la diversidad de escritos que nutren los debates estéticos: "no pueden tomarse solo en consideración los ensayos teóricos. Los primeros eslabones de una 'teoría' de la novela moderna se encuentran en los prólogos, los artículos de carácter ensayístico, las reseñas de los artistas, o integrados a sus novelas" (Vauthier, p. 34). Tomando en cuenta este conjunto de textos, el libro da fe de la existencia, en España, de cierta tradición teórica de la que emergen algunas constantes como la cuestión de la representación, la ficcionalización del autor y la recepción (Arturo Casas, p. 285-315). Rebate también un segundo tópico acerca del atraso del debate español sobre novela en relación con el que anima el campo literario más allá del Pirineo poniendo en evidencia un "concierto de voces europeas" (Vauthier, p. 40-42), relativo a un pleito antimimético, una convergencia transnacional acerca del cuestionamiento del realismo que corre en Francia de Valéry a Claude Mauriac y, en el ámbito de habla hispana, de Ortega a Pitol (Marco Kunz p. 263-283), con el paréntesis del período franquista, cuando la recepción atrasada del compromiso sartriano se enraíza en el 'anacronismo' de la dictadura. Marco Kunz observa también, a ambos lados del Pirineo, una paralela caída en desgracia de los planteamientos experimentalistas a finales del siglo XX y una pareja vuelta en gracia de la narración (p. 283).

4 El libro esboza pues una "poética histórica" de la novela (Vauthier, p. 16) estructurada alrededor de la figura pivote de Ortega y Gasset y su rechazo a la supeditación del arte a la referencia: «[1]a estética de Ortega -o lo que se creyó ver en ella- ha sido la bisagra en torno a la cual, a partir de los años veinte y treinta, ha girado y cristalizado la "querella del realismo"» (Vauthier, p.14). A partir de este enfoque se rastrean convergencias transgeneracionales. Basado en la mimesis aristotélica y el culto de la actualidad, el realismo es, según Luis Beltrán Almería, un concepto vago y polifacético que debe su continuidad y sus metamorfosis a su casi vacuidad (p. 68-74). La postura antirrealista es compartida por un miembro destacado de la "generación del 98" como Unamuno, por los Modernistas, las generaciones del 14 y del 27 (Álvarez Castro p. 89; Laget p. 114) y, en los años 60/70 por los novelistas experimentales, evidenciando afinidades que traspasan movimientos y generaciones.

5 Esta "poética histórica" de la novela fija pues su atención en las afinidades y transiciones que superen las "discontinuidades historicistas". Luis Álvarez de Castro, que rebate las categorías reductoras de la historia literaria por presuponer una “artificial homogeneización" dentro de un período dado (p. 90) propone un concepto transversal del Modernismo que tiene por prejuiciosa la dicotomía Modernismo/ 
Generación del 98 (p. 87-89), mientras que Laurie-Anne Laget y Domingo Ródenas de Moya matizan la oposición entre la novela de vanguardia y la vuelta a lo social en la “Nueva novela” promovida por José Díaz Fernández (El Nuevo Romanticismo, 1930): José Díaz Fernández y Ortega y Gasset coinciden en la necesidad de preservar las leyes del género novelístico (estructura, verosimilitud, consistencia del personaje, inmersión del lector) y apuntan, como lo hace también Juan Chabás, al riesgo de disolver la prosa narrativa en lirismo (Ródenas de Moya, p. 130-133). En la misma perspectiva, estima Natalia Vara Ferrero que "el Nuevo Romanticismo supuso un esfuerzo teórico e ideológico por aunar los recursos y las técnicas literarias de la vanguardia con una vuelta a lo humano" (p. 152). Retomando la metáfora orteguiana según la cual es incompatible contemplar el jardín tras la ventana (realismo) y mirar el mismo cristal de la ventana ('deshumanización' del arte), añade Albrecht Buschmann que si bien José Díaz Fernández, lo mismo que Max Aub, sustituyen intricados bosques a los orteguianos y pulidos jardines metafóricos, lo hacen sin renunciar a los logros estéticos de las vanguardias (p. 180-184).

El rastreo de "similitudes a distancia" se prolonga en el eco que establece Carole Fillière (p. 233-261) entre una concepción irónica de la novela y la práctica de la metadiscursividad presentes tanto en La Regenta de Clarín (1884) como en Recuento (1963) de Luis Goytisolo, casi un siglo después. El cuestionamiento de la representación es, en efecto, compartido por los dos novelistas aunque según modalidades distintas que, en ambos casos, incluyen sin embargo la écfrasis-, por estéticas realistas (clarín) como antirrealistas (Goytisolo).

7 Teoría(s) de la novela moderna en España establece las bases teóricas de un tipo de historia literaria que sustituye a criterios discriminantes que separan, incluso oponen, con el riesgo de simplificar y homogeneizar la diversidad del campo literario y de fragmentarlo artificialmente, otros criterios que permitan conjuntamente percibir las diferencias en una etapa dada, así como las transiciones, las similitudes y constantes en la distancia. Merecería prolongarse la reflexión sobre este interesante proyecto interrogando los términos que en el libro se sustituyen a la clásica terminología de las historias literarias: siglos, generaciones, movimientos, escuelas. Me refiero a términos como 'afinidades', 'continuidades' y 'convergencias'. Escribe Bénédicte Vauthier que existen afinidades formales entre los proyectos de Pérez Galdós, Baroja, Díaz Fernández, Max Aub y los escritores de la Generación del medio siglo, partidarios todos de una novela realista que se convirtió en canon de la novela moderna (p. 54). Pero, más allá de afinidades estéticas ¿no sería preciso que una historia de las formas -y no sólo de las ideas literarias- tomara en cuenta conjuntamente las prácticas de escritura, sus variantes en el tiempo y los significados que prácticas similares pueden adquirir en sucesivos contextos culturales y discursivos? 


\section{AUTORES}

\section{GENEVIÈVE CHAMPEAU}

Université Bordeaux Montaigne 